\title{
TitanTutor: An educational technology solution co-designed by children from different age groups and socio-economic backgrounds
}

\author{
Bester Chimbo ${ }^{\mathrm{a}, *}$, Helene Gelderblom ${ }^{\mathrm{b}}$

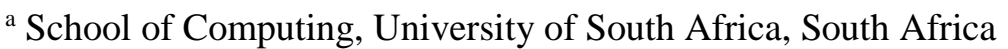 \\ ${ }^{\mathrm{b}}$ Department of Informatics, University of Pretoria, South Africa \\ *Correspondence to: P.O. Box 392, Unisa, Pretoria, 0003, South Africa. E-mail address: \\ chimbb@unisa.ac.za (B. Chimbo).
}

\begin{abstract}
Children should be included in the design process when developing new technology solutions for child users. Involving children from different age groups as well as diverse socioeconomic circumstances in participatory design is an unexplored field. In this article we discuss TitanTutor, an educational technology solution that was designed by such a combination of children using cooperative inquiry (CI). Six children aged nine or ten from a disadvantaged community and nine teenagers from privileged circumstances together designed the web-based application that would be used to provide after-school homework support to young children who lack such support. Two distinct user groups are involvedteenage tutors from privileged educational backgrounds and young tutees who live in circumstances where educational support is limited. Our aim was to investigate how existing participatory design methods such as CI should be implemented to successfully design with these groups. We describe the design-evaluation iterations that produced the TitanTutor system. The results show that designing with a mixed team of children has clear benefits but that there are obstacles that have to be overcome to reach successful design outcomes.
\end{abstract}

\section{Keywords}

Participatory design; Cooperative inquiry; Children's voice; Educational technology; Cross-age tutoring

\section{Introduction}

South Africa is an upper-middle income country, but it is characterised by extreme inequality with poverty and affluence existing side-by-side. This inequality is evident in the education system [1]. Spaull [1] refers to the "bimodal distribution of achievement" in South Africa, with the minority of learners (about 25\%) attending mostly functional schools and performing acceptably on standardised tests, while the majority (around 75\%) perform extremely poorly. There are severe problems with reading, mathematics and science education [2]. Lack of proper education in the early years of education contributes to the high drop-out rate in high schools [3]. Many South African learners do not achieve the competencies specified in the primary school curriculum [2]. E.g., in an assessment of numeracy and literacy skills, $17 \%$ of grade 3 pupils scored $50 \%$ and above in their numeracy assessment and $31 \%$ passed the literacy assessment [3]. Several socio-economic factors contribute to these poor performances, for example: no income or low income among a large proportion (i.e. around $35 \%$ in 2011) of the population [4]; many children are cared for by family or community members 
with low literacy levels who cannot provide support with homework and preparation for assessment [2]; and some households are headed by children [5].

We identified an opportunity to exploit the pervasiveness of mobile technology - even in the developing world [6] - to help with solving some of the problems in foundation phase education. Providing after school academic support to the many young children who need this could be a small step towards helping their education. TitanTutor - the technology discussed in this article - is a cross-age tutoring system intended to provide educational support to young, underprivileged children. Drawing on the "bimodal" distribution [1] mentioned earlier, the idea is that teenagers from the $25 \%$ of learners who receive good quality education will provide online tutoring to those who lack proper education. There are thus two distinct user groups - teenager tutors from privileged communities and young, disadvantaged tutees. Through participatory design (PD) with a team consisting of both these user groups, we set out to design the envisaged web-based application.

Different design techniques have been inspired by the Scandinavian PD approach that was driven by the democratic ideal that people affected by design decisions should have the opportunity to influence these decisions [7]. There has been a growing body of research on the participation of children in the design of interactive products for children, examining different levels and means of involvement that they can have during the design lifecycle [e.g. [[8], [9], [10]]]. Adults may have a good understanding of children's development and they were all children once, but they cannot know what it is like to be a child in the current social, economic and technological circumstances [11]. It is therefore important to consult children when designing for them.

The absence of children's voices in design is more pronounced in less developed societies [12]. Inadequate access to educational resources is a general problem in developing contexts and technology is often employed to address this [13]. Since children use, and are affected by, these technologies [14], they should ideally have the opportunity to participate in the design thereof. PD provides a mechanism to do this [15].

Druin [[16], [15]] also recognised the value of children as design partners and pioneered the cooperative inquiry (CI) design method that is a form of PD. In CI, child and adult design partners use brainstorming and low-tech prototyping tools to generate ideas [15]. CI teams usually consist of children between 7 and 11 and adults [17]. Since we had experience in using CI, we followed this approach to design our tutoring system. The design work started late in 2013 and the working prototype was completed at the end of 2016. Results based on the earlier stages of design have been published in [[12], [18]] and [19]. The focus there was on the mechanisms to give vulnerable children voice in design and to compare the design behaviour of young and teenage designers. In this article we continue the investigation of the young children and teenage designers but here focus on the final stages of the project and evaluate how the combination of the two groups in the design team affected the final design outcomes.

We diverted from Druin's CI method with regard to the compilation of the design team by including teenagers. The question arose whether combining teenagers and young children in a design team will affect the CI process and outcomes, particularly when these two groups come from disparate socio-economic circumstances. So, in this article we investigate the viability of involving children of different age groups and different socio-economic statuses in the design of a web-based tutoring system, using CI, by asking: 
- How does the inclusion of children from socio-economically diverse circumstances and different age groups in a CI design team, influence the design outcomes?

- What are the challenges and opportunities of working with these diverse team members in CI?

- How can future designers doing CI with teams that include children from different age groups and diverse socio-economically circumstances, overcome the challenges and maximise the benefits?

Before we explain the research methods and detailed design procedure followed to answer these questions (in Section 3), the next section provides an extract from related research that briefly discusses PD, designing with children in the developing world, designing with teenagers, and evaluating with children.

\section{Related work}

\subsection{Participatory design}

Participatory design of interactive products is characterised by active involvement of the stakeholders (most probably the users) in the design process [20]. Over the years a variety of PD approaches have been developed, including contextmapping [21] and contextual inquiry [22]. PD methods often employ brainstorming and low-tech prototyping tools to capture and demonstrate the ideas that emerge. For the past 20 years, the growing market for technology aimed at children has increasingly led to the involvement of children in the design and valuation of products aimed at them.

Cooperative inquiry (CI) is a PD technique that involves children in the design process [16] and developed out of established PD approaches. Classic CI involves intergenerational teams consisting of children between the ages of 7 and 11, and adults. The approach that we followed in designing the tutoring system was to replace the adult partners in the design teams with teenagers. The young designers in our team represent less privileged children in the 7 to 11 age bracket, while the teenagers represent older children from more privileged circumstances.

\subsection{Designing with children in the developing world}

Our study was conducted in South Africa. PD has been used widely by researchers in Europe, Canada and the United States [[8], [14], [23], [24]] but, as explained in [12], rarely in less developed contexts. Reports on PD with children in the developing world relate mostly to the health sector or education. E.g.:

- Hussain, et al. [25] worked with a design team consisting of adults and children in Cambodia to design prosthetics legs for children. This was a long term project and the three child designers were involved from 2008. They could therefore gradually get used to the researchers and the researchers gained their trust over time. The children were not involved in the PD workshops to build prototypes. They were visited afterwards at their homes and interviewed to get their feedback on the prototypes. Their results focus on two positive outcomes of PD: products that meet the young users' needs and psychological empowerment of the participants. 
- Shahid and Krahmer [26] used PD to design an educational game for promoting basic reading and writing skills of early teens in Pakistan. This was done through two separate five-day PD workshops with illiterate preteens and adult designers. The children do not attend school and all have daily jobs. In the second workshop parents interfered with the design process. Some fathers attended the design sessions and the children were clearly inhibited by their presence. Other methodological obstacles included language barriers, power distance, cultural issues, and timing restrictions.

- Mills-Tettey, et al. [27] evaluated a computer-based reading tutor in Ghana and Zambia with children in grades 2 to 4 . They observed the children using the application so no real co-design was involved.

These studies indicate some positive outcomes of PD with disadvantaged children (e.g. psychological empowerment) and some difficulties relating to the context (e.g. power issues). None of these researchers report on specific design contributions made by the children or on the challenges relating to the cooperation between the children in the design teams.

\subsection{Designing with teenagers}

Teenagers are regarded by some as challenging to work with [[28], [29]]. They strive for their own identity and question adult-child power relationships [28]. This, together with their stronger self-consciousness may result in conflictive relationships with adults. It may also cause teenagers to have lower motivation for engagement in PD [30]. Janet Read and coworkers [e.g. [[31], [32]]] have been advocating for involving teenagers in PD and in their reports the advantages of working with teenagers seem to surpass the difficulties. We hope to provide further insight into co-designing with teenagers in this article.

\subsection{Evaluating with children}

As any design process should, our approach included several design-evaluate iterations. Of the three evaluation sessions, two involved children. A popular evaluation method with children is the Smiley Face Likert scale called the 'Smileyometer' [33] that provides an accessible way for children to rate usability and user experience aspects of a design. The tool consists of smiley faces that range from negative (sad) to neutral to positive (very happy), from which children can choose to indicate their assessment of an aspect of a product.

Another method involves sticky notes on which children freely describe their experience, perceptions and opinions about usability [34]. Research has shown that children have difficulty expressing their feelings and thoughts through words, but their actions and behaviour reflect their thoughts. Facilitators can help children articulate their thoughts on the sticky notes by asking them to express their opinions in the form of likes, dislikes and design ideas. Since we were not testing a fully functional system we opted for the sticky notes. Also, we were interested to hear the children's ideas and recommendations rather than obtain a quantitative scoring of the design.

\subsection{Summary}

The discussion above suggests that when combining teenagers with young underprivileged children in CI we need to be especially aware of the power imbalance between the groups. 
Teenagers are at a stage where they want to show their independence and growing maturity and will enjoy being looked up to by the younger children. While the age difference creates this power distance, the difference in socio-economic backgrounds could amplify the imbalance. In our planning, these were important considerations because we needed the groups to have equal voice. We discuss our design methods next.

\section{Methods}

In this section we describe the details of our design methods. Since this research was done through design, our research and design methods overlap. Our choice of CI was motivated by the authors' experience with this PD method and not by the fact that we think it is necessarily superior to other PD methods with children. Evaluation is an essential aspect of any iterative design process, so we also describe the various evaluation methods used. Many details that have been explained in related work [[12], [18], [19]] are not included here, but we do repeat some aspects for the sake of context and coherence.

\subsection{Overview}

Our design team consisted of teenagers from privileged communities and young children from disadvantaged communities. The overall process involved:

1. Identifying a community of underprivileged children to partner with.

2. Recruiting teenage designers.

3. Exposing the design team to the design problem and context through face-to-face tutoring sessions.

4. Conducting design sessions using CI.

5. Analysing the design data and iteratively evaluating and building prototypes.

6. Implementing the solution.

Steps 1 to 4 and part of step 5 have been discussed in [12] and [19]. In this article we focus on steps 5 and 6 and reflect on the overall project to extract guidelines for designing with a mixed-age, mixed-circumstances design team.

\subsection{Participants}

The underprivileged children that we recruited live in a privately run children's home. The children have mostly been placed there by a court of law due to abuse or neglect. They attend government schools and receive good care at the home, but staff expressed a clear need for individual academic support. The staff selected six children in grades three and four (aged nine or ten) for our team - three boys and three girls. The only selection criteria were age and school attendance. We refer to them as 'the young designers'.

We recruited nine teenage volunteers from privileged communities by word of mouth. Their ages ranged from 14 to 17 . Although we did not specifically favour girls, all were female.

All fifteen children were involved in the design of the first, static prototypes (discussed in Section 4.1). Thereafter three teenagers and three young designers from the team participated in the first round of evaluation and redesign, purely based on availability. For evaluation of the online prototype we recruited four new young participants (not from the children's home) 
and three new teenage participants, so as to include evaluators who were not involved in the design before.

\subsection{The design sessions (data collection)}

The initial face-to-face tutoring at the children's home demonstrated the power imbalance between the tutors and tutees [19]. The young children viewed the teenagers as adults. Based on this observation we predicted that the design sessions would be dominated by the teenagers if we combined them from the outset. To avoid this we first had a design session with the teenagers alone and then conducted sessions with the younger partners where teenagers acted as facilitators. More details are available in [18] and [19].

We conducted two sessions with the young designers. The first was to address power issues, to create the awareness that they can be real designers, and to expose them to different kinds of mobile technologies (see [12] for details). The second was a CI session with groups of three that included one teenager each. The teenagers understood that the ideas should mainly come from the young designers and that they should play a facilitator role.

Low-fidelity paper prototypes and big ideas captured the key functional requirements and interface design ideas of the designers.

\subsection{The design outcomes (data analysis and first round evaluation)}

Analysis of the low-fidelity paper prototypes, children's explanations of their designs and the recorded big ideas, informed the next level of prototypes in higher fidelity. Both authors analysed this data qualitatively in cycles of comparative analysis of video recordings of presentations, big ideas, and the physical attributes included in the prototypes. In our organisation and coding of the data we specifically looked for elements to include in the design of the tutoring application, paying attention to the similarities and differences between the contributions made by the teenagers and young designers respectively. The analysis yielded seven themes that are discussed in Section 4.1.

Based on the analysis, we developed a high-level flow diagram (see Section 4.2) that reflects the broad requirements of both groups of designers. This was expanded into a detailed interface design accompanied by usage scenarios.

We presented the detailed design to three young designers and three teenagers in a group discussion at the children's home for evaluation. Every page was displayed on a big screen and explained to the evaluators. They were asked to comment and recommend additions or changes. During this session the name of the application was finalised. The two-hour discussion was recorded and analysed and the results incorporated into the functional and technical specifications for the high fidelity, web-based prototype.

\subsection{Implementation and further evaluation}

A team of independent developers implemented the web-based prototype according to design mock-ups and functional and technical specifications. The development involved two implement-evaluate iterations. The researchers evaluated the first version against the design requirements and conducted a lab based usability evaluation on the improved version. 
Seven teenagers (including three from the design team) and four young children (all new), two researchers and two developers participated in this evaluation. The evaluation started with a discussion circle to brief the new participants and explain how the evaluation would proceed.

We used two methods of evaluation namely 'sticky notes' [24] and a group discussion. First the evaluators played around with the system in pairs and provided their likes, dislikes and design ideas [24] on sticky notes. In the group discussion, developers stepped through all the functionalities on a large screen, allowing the children to ask questions and make comments. Facilitators recorded the group's feedback on sticky notes, also as likes, dislikes or design ideas.

The results of the lab based evaluation were analysed by organising the likes, dislikes and design ideas into themes and synthesising the results into recommended changes. These recommendations were then included in the final version of the web based prototype.

\section{Analysis, results and reflection}

We organise this discussion according to the different rounds of prototyping.

\subsection{Results of the first round of design}

The three design sessions yielded six low fidelity design mock-ups (e.g. Fig. 1, Fig. 2) and two sets of 'big ideas' (e.g. Fig. 3). Results of analysis of the prototypes were divided into contributions by the teenagers and contributions by the young designers. The list of ideas presented by the teenagers was notably longer than those from the young designers. The teenagers' design content made it easier to interpret their ideas and they could describe the full functionality of their designs. The young designers' prototypes were more decorative, had fewer functional elements than those of the teenagers (see Fig. 3) and they struggled to provide a coherent description of how the interaction would proceed. The teenagers who facilitated the young designers' sessions assisted during the presentations and helped to articulate the young designers' ideas. Despite the obstacles, the young designers' voices came through - for example, they insisted on a customisable interface, wanted their identities visible on the design and emphasised rewards for good progress.

Analysis of the design data revealed seven themes under which we compare the contributions of the two groups: 

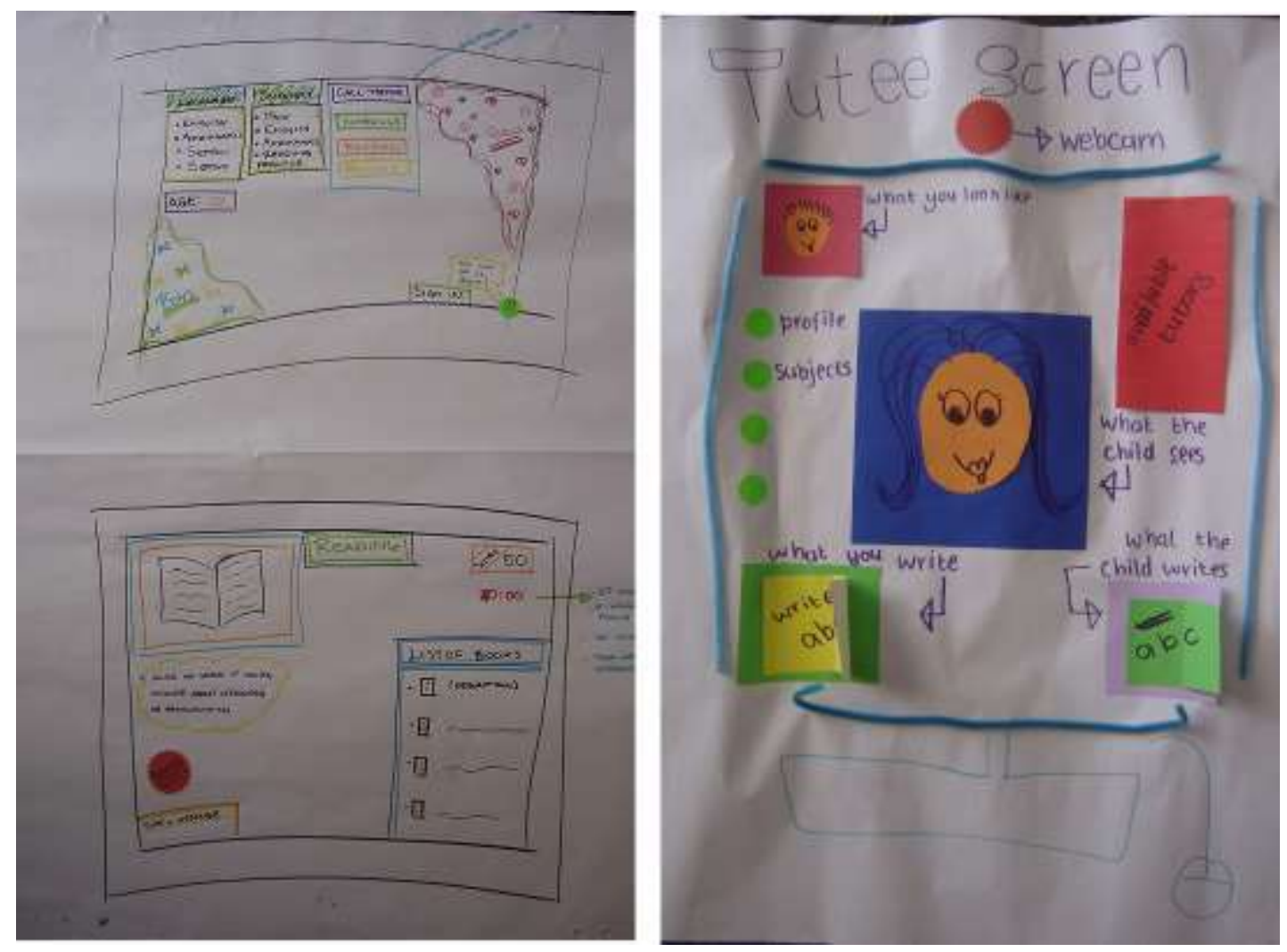

Fig. 1. Paper prototypes of two teenage groups.

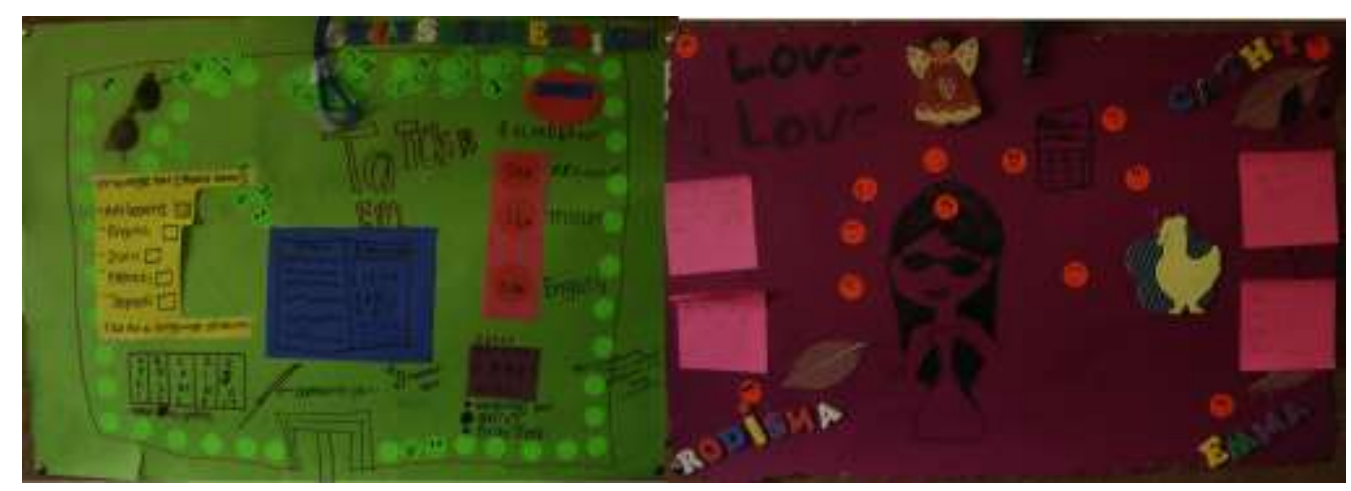

Fig. 2. Paper prototypes of two young design groups. 


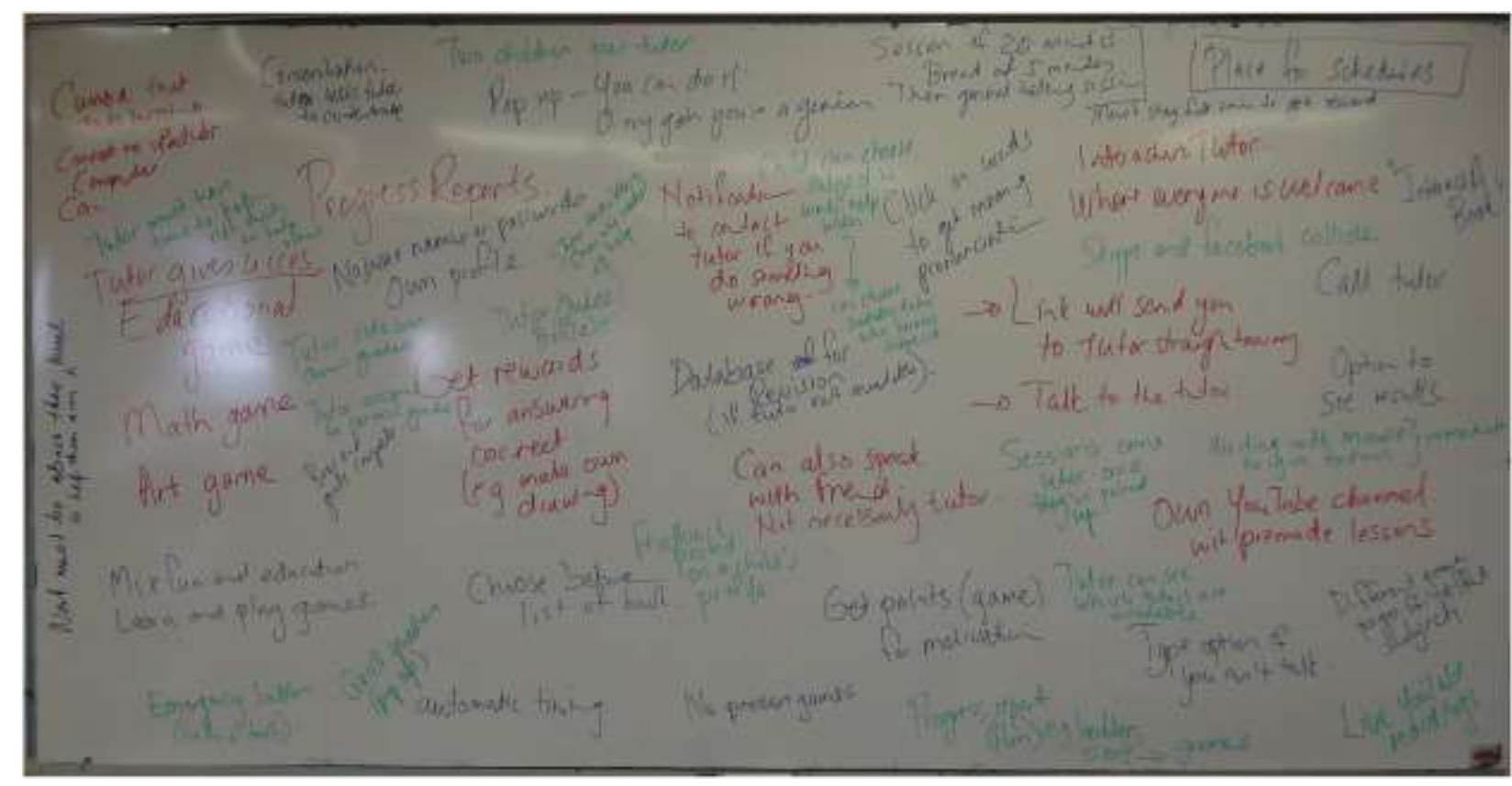

Fig. 3. Tutors' 'big ideas'.

\section{High-level interface design}

Teenagers distinguished between a tutor view and a tutee view, while the young designers proposed one interface. Both groups wanted indication of who was currently available. The young designers suggested games for when tutors are not available, whereas teenagers proposed formal exercises to practise skills. The young designers wanted their own identity to be visible. All agreed on the need for secure access, using password protection. Despite their lack of exposure to technology, the young designers were fully aware of 'bad people' on the internet.

\section{Communication mechanisms}

Both groups wanted on-screen writing tools - the young designers were satisfied with a mouse and keyboard, whereas the teenagers proposed a stylus. Both groups thought of synchronous and asynchronous uses of the system. Some young designers requested a choice of language, while the teenagers assumed English would be used. The teenagers were from four different language groups and the fact that they spoke only English during the design sessions would explain this assumption. The young designers used both Afrikaans and English during their sessions. Since some of the teenagers did not speak Afrikaans, there were some language issues. Both groups included asynchronous messaging, text-based chat, face-to-face chat and a white board.

\section{Additional features}

Everybody wanted access to computer games as learning tools. The teenagers suggested a YouTube-like channel (called MeTube) for storing recordings of tutoring sessions for later use, or where tutors can upload helpful educational videos. They also requested a way for tutors to communicate with one another to exchange tutoring ideas. Both groups included an image library. 


\section{Rewards and motivation}

All designers agreed on the need to reward progress. The teenagers proposed access to computer games as a reward, while the young designers proposed virtual rewards such as onscreen flowers, stars and chocolates.

\section{Monitoring progress}

All agreed that the system should monitor and evaluate tutee progress to provide feedback to both tutee and tutor. Teenagers placed a lot of emphasis on recording the tutees' progress and tailoring the interaction according to that.

\section{Social media elements}

Designers were influenced by familiar social media. The teenagers proposed features from YouTube, Facebook and Twitter, while the young designers proposed elements from Google applications. Nobody wanted just a Skype-like interface to talk synchronously.

\section{Other psychological and practical issues}

Teenagers considered practical issues such as their own time constraints, suggesting that tutors should have fixed time slots and should not feel 'pushed' to do it. During the face-toface tutoring period some of the tutors and tutees formed attachments. The teenagers therefore felt tutors and tutees should be able to choose who they work with. During further iterations of the design this idea was discarded in favour of a more anonymous rotation system so that tutees do not become too attached to specific tutors who may at some point leave the system.

At the end of the design sessions we asked each design team to suggest a name for the system. The researchers picked 'Broccoli Buddies' from those suggestions as a placeholder name for the first round of design. The name was further discussed during later evaluation sessions (details are provided in the next section).

\subsection{High level flow diagram and detailed interface design}

Fig. 4 shows the flow of user interaction. All users go through a login process. When users first register they choose a profile picture and user name from the list of avatars and names. The superhero theme came from the teenagers and would be discussed during an evaluation session. Users can choose a colour scheme, indicate their language preference and set a password. Each care facility using the application will be a closed group with an administrator to monitor activities, endorse passwords and screen tutors. The administrator will assign tutees and tutors to specific tutee groups. A tutor can belong to more than one group.

The profile page designs appear in Fig. 5, Fig. 6. The tutee can send a message, upload and download an image, edit their profiles by changing appearance etc., visit the play and learn store and make voice/video calls. The video/audio chat also has a white board facility. 


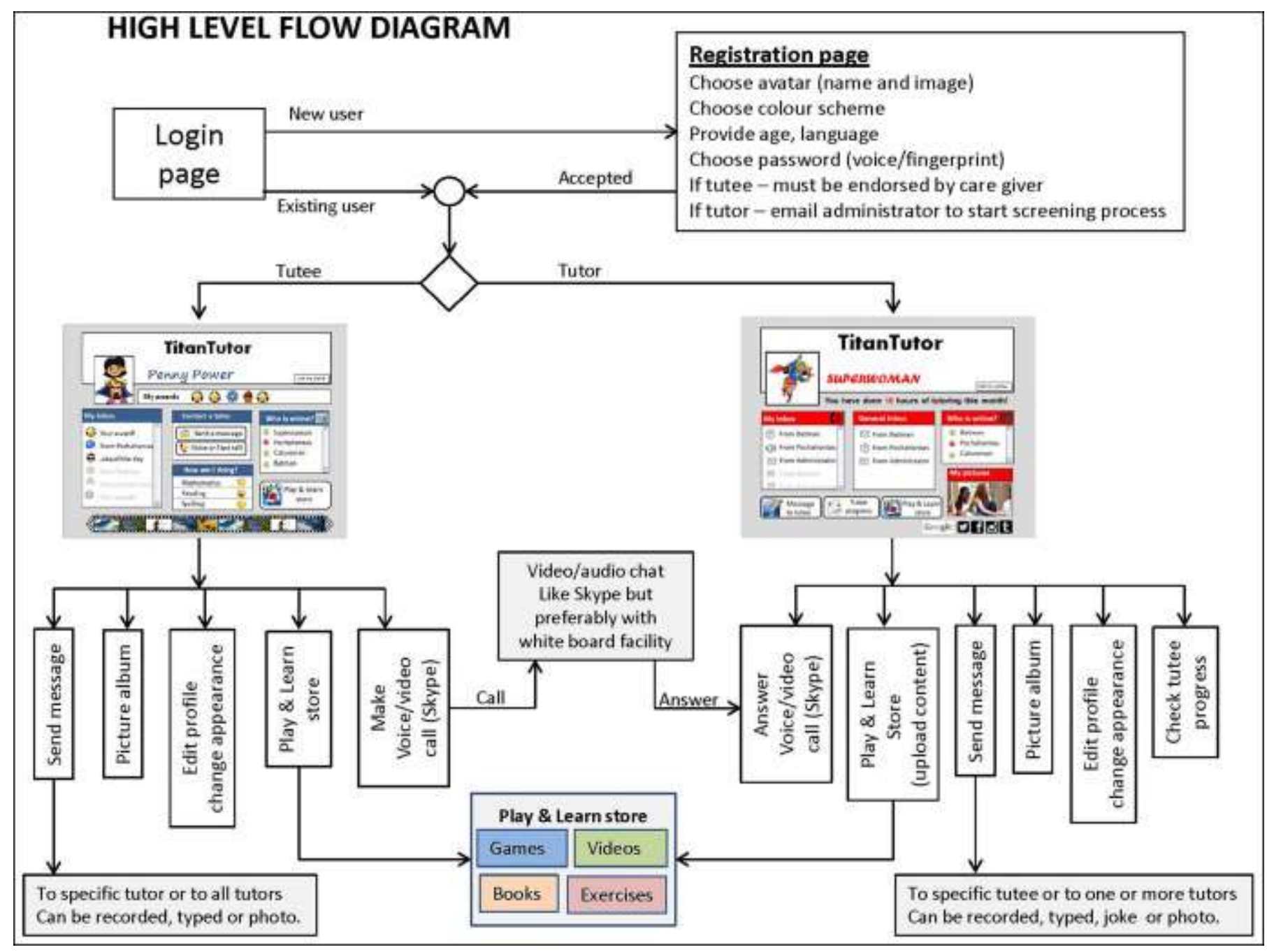

Fig. 4. High-level flow diagram.

The tutors can answer voice/video calls, upload content into the play and learn store, send messages to specific tutees or to groups of tutees. They can check and edit tutee progress and edit their own profiles.

Personal inboxes provide an asynchronous communication mechanism. Message types are award, joke-of-the-day, text messages, marked exercises, voice notes and images. An urgent message will have a designated icon (e.g. big red H). Awards sent to the tutee inbox are transferred to the awards strip when the tutee opens it. The tutor page has a general inbox that is visible to all tutors and any tutor can respond to requests posted there.

Colours and fonts are customisable. Should a user change their avatar identity they would lose awards collected until that time. A clear warning must be displayed about what they will lose. The system keeps record of the time the tutor has been available in the current month as a reminder of their commitment and to acknowledge their participation. The Who's online? box shows who are currently available and the schedule icon on the box's title bar brings up a weekly or monthly schedule showing the tutors' availability. Tutors can edit their own availability. 
In the Play and Learn Store tutors can upload games, books, exercises and videos for the tutees.

As discussed in Section 3.3, this design was evaluated by three teenagers and three young designers in a group discussion at the children's home. Based on this evaluation the appearance of the awards, the choice of icons to indicate progress and the theme were finalised. This evaluation session also included an extensive discussion of the name of the system and after much debating the children agreed on TitanTutor as it reflects the purpose of the system and a positive, powerful image.

We also created two usage scenarios to illustrate the purpose and functionality of the system. These scenarios were included in the specification to provide the developers with tangible contexts of use. Fig. 7 shows one scenario.

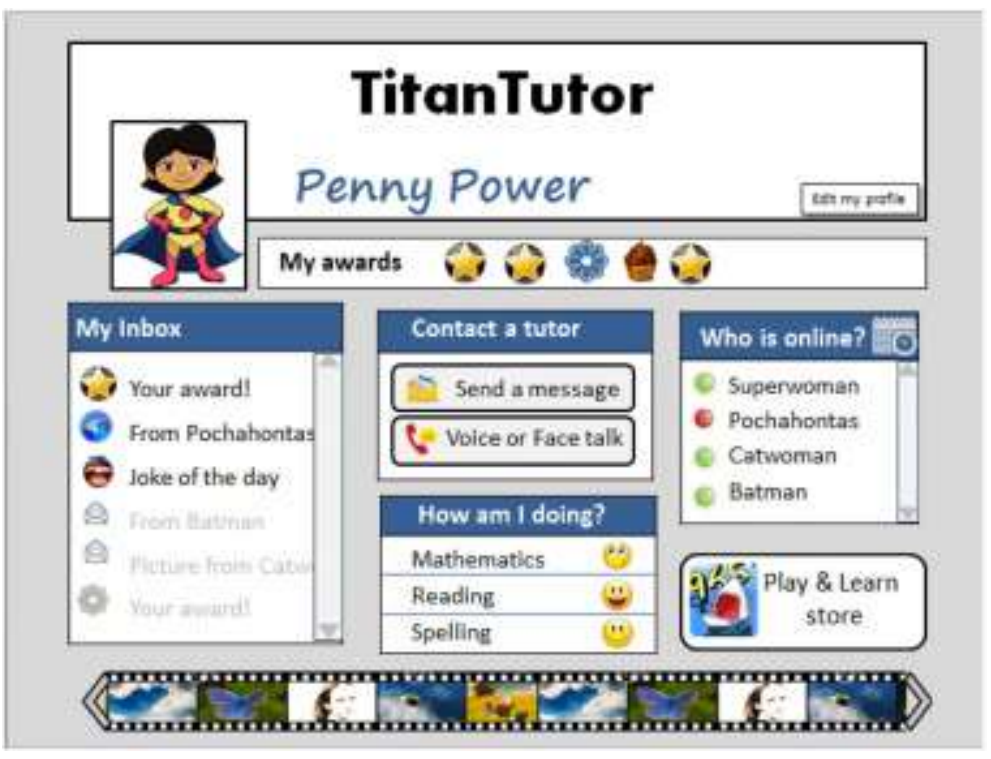

Fig. 5. Tutee profile page.

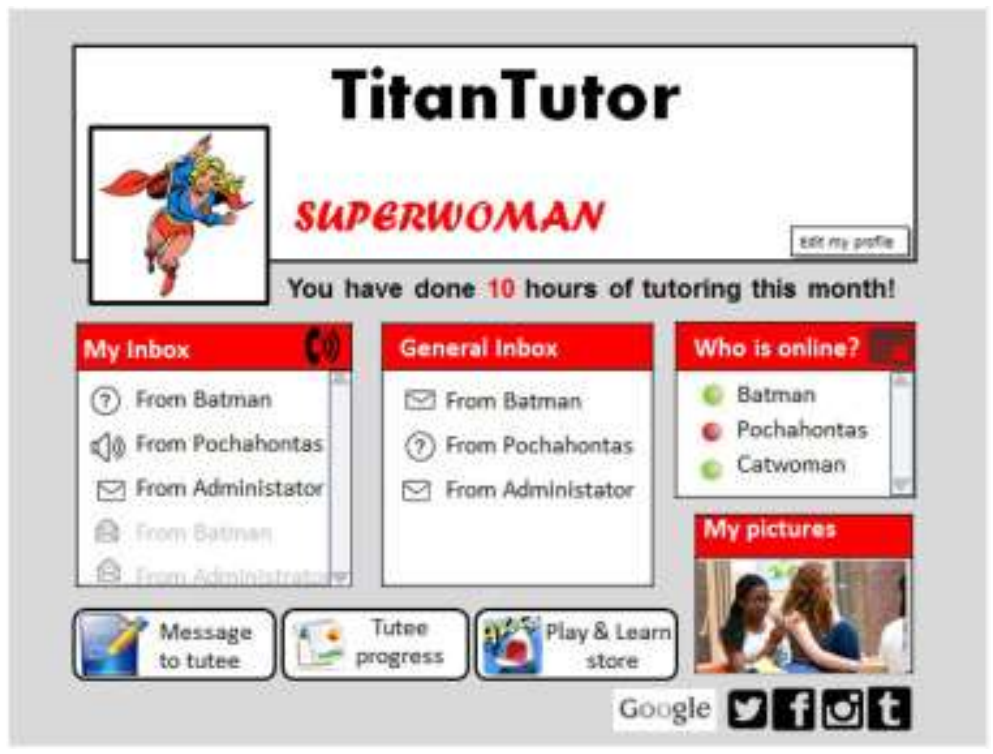

Fig. 6. Tutor profile page. 
Two programmers developed the static prototype and usage scenarios into an interactive, web-based solution. The implementation tools included HTML 5, CSS3, ASP.NET, JavaScript, JQuery, WebRTC and Twiddla. Images of the avatars are preloaded and for the first round of implementation we assigned fixed names to the avatars. Within a group no two members can use the same avatar. The images were obtained from sources that make them available for free.

\begin{abstract}
SCENARIO 1
Penny Power lives in a centre for abandoned children where school children have limited, supervised access to the intemet from the care centre's mobile devices for short periods of the day. Penny is in grade 3 and her homework for today is to read two pages from her English reading book and they are writing a times- 6 test in math. Penny logs into to Broccoli Buddies and sees that Superwoman - her favourite tutor - is online. She clicks on Send a Message and selects Photo Message. With the tablet's camera she takes a photo of the two pages she has to read and sends them to Superwoman. She then clicks the Voice/Face Talk button and selects Superwoman from the contacts. She knows the care centre has limited internet access so she requests a voice call. Superwoman answers and after saying their hellos she asks Penny what she can help with. Penny says that Superwoman should open the reading material in her Inbox so that Penny can read to her. Superwoman listens while Penny reads and corrects and helps her as she goes along. She makes sure to comment with "Well done" every now and then. Penny then asks Superwoman to ask her the $x 6$ tables to practice for the test. When they're done with that they say goodbye and end the call. Superwoman then clicks on Tutee progress and updates Penny Power's information to indicate that she knows the $x 6$ tables and changes the progress icon to a big smiley. She also sends Penny a Flower award to show her appreciation for Penny's hard work.
\end{abstract}

Fig. 7. Example of a usage scenario.

During the final lab based usability evaluation, evaluators used the system in pairs and recorded their individual feedback on sticky notes. Facilitators helped the young evaluators to write down their ideas. Fig. 8 shows the lab setup and Fig. 9 the organisation of feedback gathered during evaluation.

The recommendations that emerged from the evaluation related to the interface rather than the functionality. These included bigger fonts and awards; more awards and avatars; adding a scroll bar to the inbox; adding tooltips to explain elements; and including characters that will appeal more to teenagers. Some problems they experienced with the system were linked to the lab setup and network restrictions. The whiteboard was not fully functional and those who were not using headphones struggled with the video and audio communication.

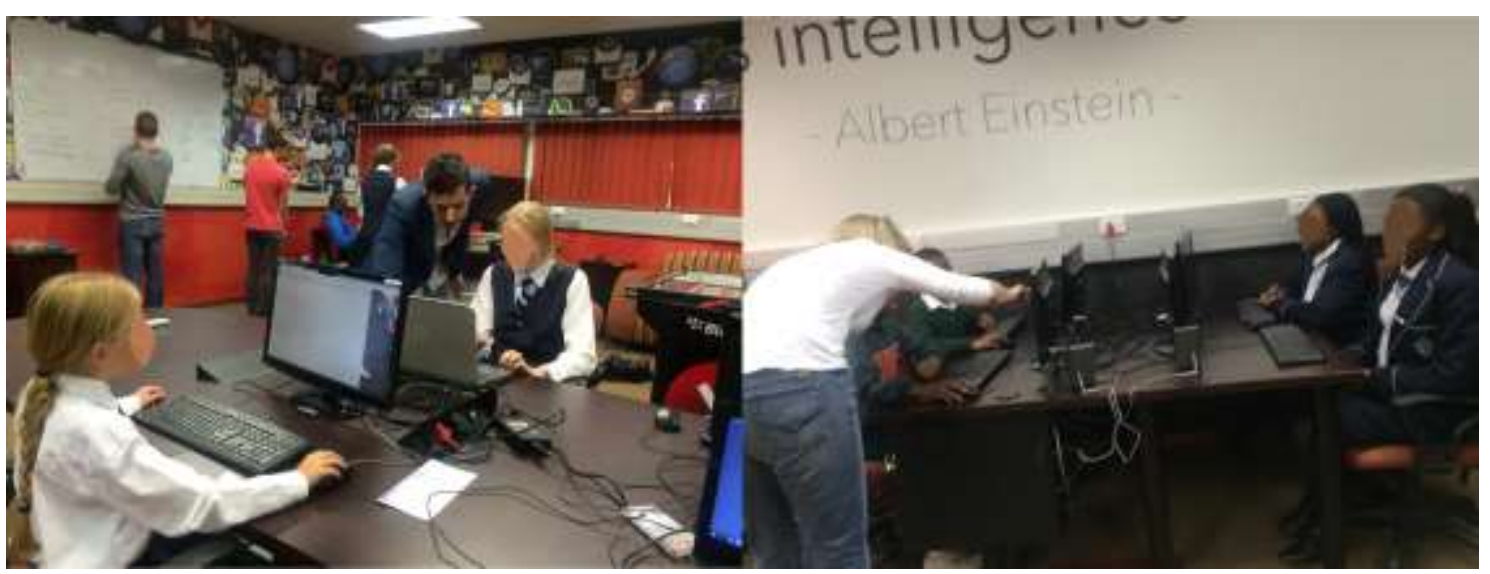

Fig. 8. Evaluators working in pairs. 




Fig. 9. Organisation of sticky notes into categories.

Fig. 10, Fig. 11 show a selection of screens of the web based prototype.

The image library was removed in the final version because it would be difficult for the administrator to continuously monitor the images to ensure that they do not compromise the children in any way.

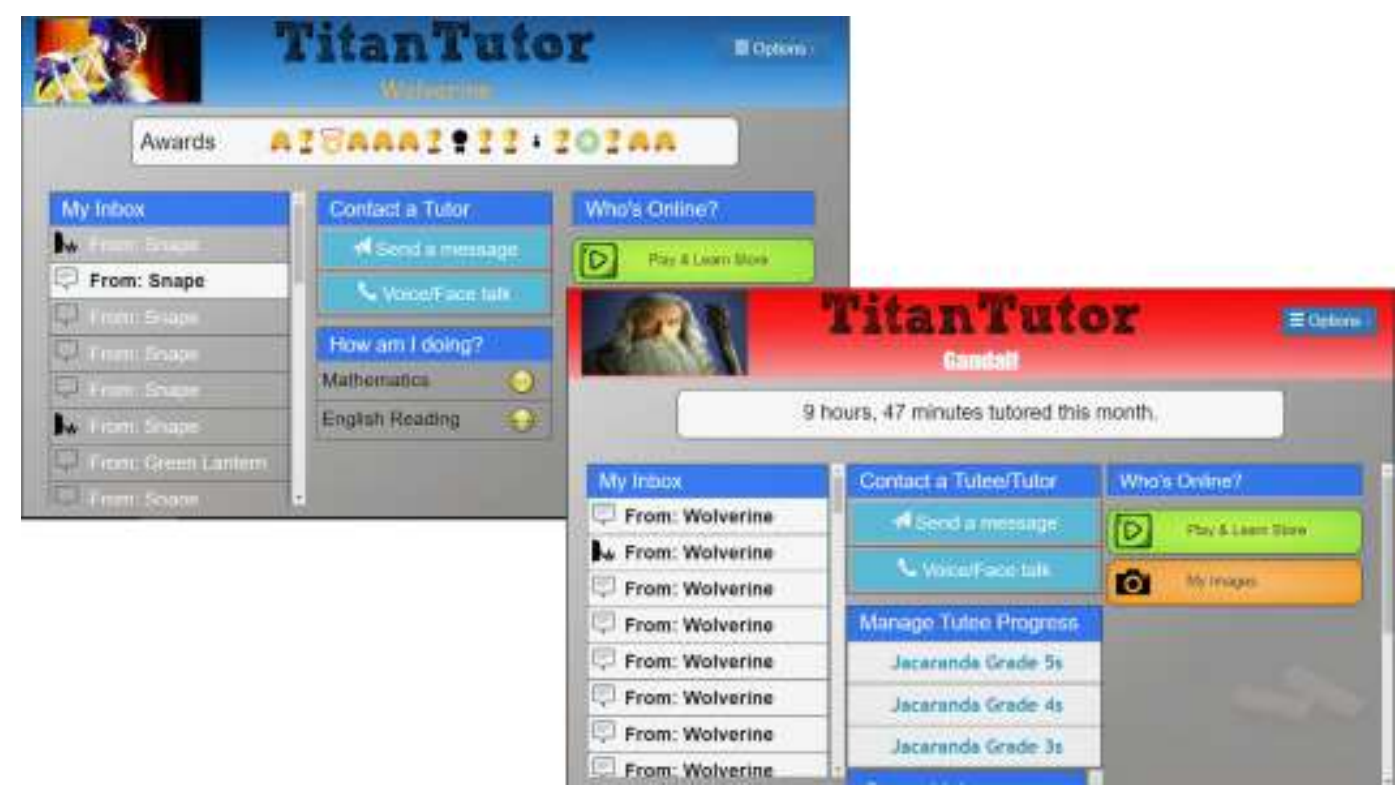

Fig. 10. The profile pages. 


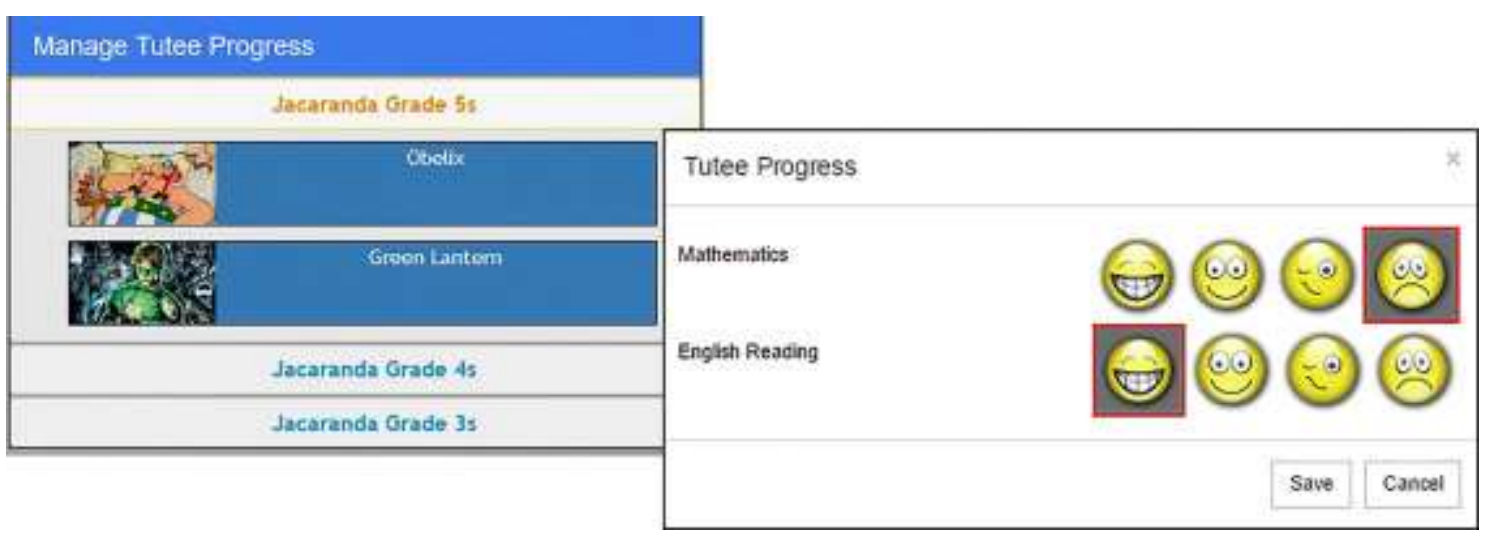

Fig. 11. Managing tutee progress.

\section{Discussion of the results}

We set out to answer three research questions. The first relates to the design outcomes of the CI process and how this was influenced by the diversity of the design team. The first part of the question was answered in Section 4 with a detailed discussion of the design outcomes. Section 5.1 deals with the second part of the question. The second question relates to the opportunities and challenges when using CI with a diverse design team (Section 5.2 Benefits of doing CI with children from diverse backgrounds and age groups, 5.3 Challenges when designing with the two diverse groups) and the third question relates to guidelines for future design with such diverse teams. We answer the last question in Section 5.4.

\subsection{How the diversity of the team influenced the design}

We answer this question by considering how the outcomes would have changed had we included only one of the groups in the team. If we designed with teenagers only, they would not have met the young designers in the context of the care facility. Their feedback after the month of familiarisation (as discussed in [18]) indicate that they would not have understood how attached they could get to the children (saying for example: "I didn't expect to become emotionally attached to the kids, but yes") and how dependent the children could become on them (e.g. "I just want that they will come and help us forever"). This influenced the teenagers' design decisions. For example, they supported the anonymity provided by avatars and decided, in the second round of design, that tutors and tutees should not be paired one-toone. Also, the teenagers wanted a rather involved monitoring and reward system with games becoming available as tutees reach specific levels of performance. This idea was replaced after the session with the young designers who preferred to simply receive symbolic badges or candy as reward. The young designers' lack of exposure to technology was evident in such more modest requirements.

Had we not included teenagers with lots of exposure to technology and social media in particular, a number of features may not have emerged, for example, the video chat combined with a whiteboard and the play and learn store where educational games and videos can be accessed. The teenagers' facilitation of the young designers' session had a notable effect on the young designers' behaviour and design contributions. The teenagers encouraged them to use the available materials, prodded them for ideas and eventually helped them to express these ideas during the presentations. It is difficult to provide tangible evidence that the young designers would have contributed less had they worked with adult partners, but our 
observations lead us to believe that the successful partnership and lively communication between these diverse partners were influenced, on the one hand, by the teenagers' empathy and the sincere interest they showed in the children, and, on the other hand, by the young designers' admiration of the teenagers and their appreciation of this unlikely partnership. More can be read about this in [12] and [18].

\subsection{Benefits of doing $\mathrm{CI}$ with children from diverse backgrounds and age groups}

A known benefit of $\mathrm{CI}$ is that it is an empowering experience that results in participants gaining self-confidence [[15], [23]]. We clearly noted the empowerment benefit amongst the young designers. At the start of the project they were shy to express their ideas and when they had to present the prototypes they were all reluctant to talk. However, during the first evaluation session, when they had realised that we actually took their ideas seriously, they became very involved in the discussion and expressed their opinions confidently (e.g. "if you are not good in maths you must of course get a sad face", "or use polka dots - I really love polka dots", “oooeee, I have a good idea!"). They were constantly making jokes ("thanks heavens the camera is not pointing to J otherwise it would have broken", "I just want to know when we're going to get [this tutoring system]"). The transcriptions of that session show that the young designers talked notably more than the teenagers.

The role of design facilitators motivated the teenagers to engage. They were always eager to participate, took responsibility for the design and their interaction with the young designers was exemplary. Although the young children looked up to the teenagers, the teenagers' honest, playful and caring attitude created a safe communication space. The children wanted the teenagers' attention and this encouraged them to participate in the design. When it was time to present their designs, the young designers were shy, but the teenagers stepped in to help them to convey their ideas.

From a design point of view there were clear benefits of involving both groups. The young designers had more modest expectations and this led to a design that is simpler and easier to implement than what we would have produced with teenage input only. If a virtual flower is sufficient reward for good performance, why complicate matters with an intricate scoring and reward system? The young designers were imaginative (e.g. they requested a "computer pen"), though not always practical, while the teenagers contributed more in terms of functional aspects. Real interaction with the intended users made the teenagers aware of the actual value they may contribute and the effect the tutoring can have on themselves (e.g. "It is different from what I expected. It is very emotional.”).

\subsection{Challenges when designing with the two diverse groups}

Identifying young design partners from an underprivileged community was difficult. Our ethical clearance required us to be very specific about how, where and when we would interact with them, who would give permission and who from their community would oversee the activities. We therefore approached formal care facilities and were fortunate to find one that was keen to work with us. We were however restricted by their daily schedule and could only visit them on certain weekdays for 90 min maximum.

Teenagers from privileged communities participate in a large variety of extra mural sport and cultural activities at their schools. Matching their schedules with our own and that of the children's home was a real challenge that prolonged the time frame of the project. 
The age gap between the two groups had a notable effect on their relationship. Initially the young designers treated the teenagers like adults (calling them "ma'am" or "teacher").

Fortunately, the month of face-to-face tutoring exposed these power issues. We could advise the teenagers on addressing this imbalance before the design sessions started by, e.g., letting the children stand at a white board and act as teachers while the teenagers sat on the floor acting like their pupils.

By the end of the face-to-face sessions, communication patterns and behaviour indicated that the children still viewed the teenagers as their superiors, so we started with a teenagers-only design session. The teenagers were also new to CI so they needed to practise the prototyping skills before they could transfer them to the young partners. The young designers gradually adjusted and could eventually express their ideas freely in front of the teenagers (refer to Section 5.2 for examples).

It was important that the children understood from the outset that the project would have a beginning and an end. We realised that attachments could be formed and had to deal with that sensitively. The teenagers were briefed beforehand by a psychologist on how to act towards the children and how to deal with potentially difficult situations. She explained to them how to set boundaries and what incidents to report to caregivers or the adult researchers [18]. For example, when the children start to tell them personal stories, they had to steer the conversation back to the tutoring or design activities saying for example "we can talk about that again later, but we now have to finish this first". The psychologist also explained that the teenagers should be careful not to believe everything they were told and that when anything upsetting or alarming was communicated to them, they had to report it to an adult.

\subsection{Guidelines for designing with children from diverse backgrounds and different age groups}

The challenges we faced and our suggested responses are summarised in the following broad guidelines:

Prepare ways to address the power imbalance between the two groups early on. E.g., let them engage in activities before the design sessions where the young children feel they have some authority over the teenagers.

Ensure that the teenagers understand the young designers' context by immersing them in the underprivileged world of the young partners before they design.

Include one non-design session during which the young designers are given games and activities that instil confidence in their own voice, expose them to new technologies, and familiarise them with all the people involved.

Design with the teenagers separately first and then let them facilitate design sessions with the young designers. The teenage facilitators should understand that they have to allow the young children to voice their ideas and that every idea counts. In subsequent design-evaluation iterations they can work together as equal partners.

Expect scheduling problems because each group comes with their own set of time restrictions and activities related to their respective contexts. 
Prepare the teenagers to deal sensitively with the children and to create an emotional distance so as to prevent too strong attachments. Involving a qualified psychologist is advisable.

\section{Conclusions}

This article reports on a design project with the goal to support children's basic right to education. Thousands of children in South Africa lack proper educational resources and researchers have the responsibility to address this. In our project, teenagers from privileged communities and young children from underprivileged communities co-designed a cross-age tutoring platform for after-school academic support to young children who lack such support. The focus of this article was on the outcomes of the design and how the diversity of the designers affected the design process as well as the resulting prototype application.

Our results demonstrate that it is feasible to engage children of different age-groups and socio-economic backgrounds in PD. Each group made unique contributions and their collective input yielded a successful design outcome. Although there were complex issues to deal with, such as familiarising the teenagers with the young children's context, addressing the power imbalances and being sensitive to the effects of the young designer's circumstances, the rewards in the form of the feasible TitanTutor prototype, bridges that were built between two disparate groups of children and the empowering effect on all the designers involved, justify the effort. Based on our experience, we have made some recommendations for future designers doing CI with teams that include children from different age groups and diverse socio-economically circumstances.

We are currently applying for funding to do a pilot implementation of TitanTutor at two care centres - one city-based and one in a rural location with mobile internet facilities provided. Once the problems that emerge during this pilot study have been addressed we will work towards broader deployment. Our main obstacle is to obtain the necessary funds.

\section{References}

[1] N. Spaull, Poverty \& privilege: Primary school inequality in South Africa, Int. J. Educ. Dev. 33 (5) (2013) 436-447.

[2] N. Spaull, South Africa's education crisis: The quality of education in South Africa 1994-

2011, Centre for Development and Enterprise. Report Commissioned by CDE, Johannesburg, Pretoria, 2013.

[3] Department of Basic Education, Report on annual national assessments (ANA) Grades 16 \& 9. Department of Basic Education, Pretoria, South Africa, 2011.

[4] Stats SA, Census 2011: Income Dynamics and Poverty Status of Households in South Africa. Published by Statistics South Africa, 2015.

[5] S.M. Mogotlane, M.F. Chauke, G.H. van Rensburg, S.P. Human, C.M. Kganakga, A situational analysis of child-headed households in South Africa, Curationis 33 (3) (2010) $24-32$.

[6] T. Mawela, Exploring the role of social media in the G2C relationship A South African perspective. Information Development, 2016, p. 0266666916639743.

[7] P. Ehn, Scandinavian design: On participation and skill, in: Participatory Design:

Principles and Practices, 1993, pp. 41-77. 
[8] A. Kano, J. Read, Doing girly stuff in the semi structured design activities- and the point is? Workshop on Child Computer Interaction: Methodological Research at Interact, Preston, 2005

B. Chimbo, H. Gelderblom / International Journal of Child-Computer Interaction 15 (2018) $13-2323$

[9] L. Benton, A. Vasalou, R. Khaled, H. Johnson, D. Gooch, Diversity for design:

A framework for involving neurodiverse children in the technology design process, in:

Proceedings of the 32nd annual ACM conference on Human factors in computing systems, 2014, pp. 3747-3756.

[10] A. Weightman, N. Preston, R. Holt, M. Allsop, M. Levesley, B. Bhakta, Engaging children in healthcare technology design: developing rehabilitation technology for children with cerebral palsy, J. Eng. Des. 21 (5) (2010) 579-600.

[11] J.A. Fails, A. Druin, M.L. Guha, Designing mobile interfaces and interactions for children using cooperative inquiry, in: CHI 2009, Boston, MA, USA, 2009.

[12] H. Gelderblom, Giving children voice in the design of technology for education in the developing world, S. Afr. Comput. J. (SACJ) 54 (2014) 34-42.

[13] R.B. Kozma, W.S. Vota, ICT in developing countries: Policies, implementation, and impact, in: Handbook of Research on Educational Communications and Technology,

Springer, New York, 2014, pp. 885-894.

[14] A. Roy, P. Kihoza, J. Suhonen, M. Vesisenaho, M. Tukiaianen, Promoting proper education for sustainability: An exploratory study of ICT enhanced problem based learning in a developing country, Int. J. Educ. Dev. Inform. Commun. Technol. (IJEDICT) 10 (1) (2014) 70-90.

[15] A. Druin, The role of children in the design of new technology, Behav. Inf. Technol. 21 (2002) 1-25.

[16] A. Druin, Cooperative inquiry: Developing new technologies for children with children, in: M. Williams, M. Altom (Chairpersons) (Eds.), Proceedings of the SIGCHI Conference on Human Factors in Computing Systems, ACM Press, New York, 1999, pp. 592-599.

[17] M.L. Guha, A. Druin, J.A. Fails, How children can design the future, in: Proceedings of Human-computer interaction, Vol. 4, 2011, pp. 559-569.

[18] H. Gelderblom, J. Yip, J.E. Bonsignore, B. Chimbo, Self-recorded audio feedback as a means to allow young, vulnerable children to participate in design, IDIA, 2014.

[19] B. Chimbo, H. Gelderblom, Comparing young children and teenagers as partners in codesign of an educational technology solution, in: Proceedings of the ISI e-Skills for Knowledge Production and Innovation Conference, Cape Town, South Africa, 2014. [20] C. Spinuzzi, The methodology of participatory design, Tech. Commun. 52 (2) (2005) $163-174$.

[21] F.S. Visser, P.J. Stappers, R. Van der Lugt, E.B.N. Sander, Contextmapping: experiences from practice, CoDesign 1 (2) (2005) 119-149.

[22] K. Holtzblatt, S. Jones, Contextual inquiry: A participatory technique for system design, in: Participatory Design: Principles and Practices, 1993, pp. 177-210.

[23] M.L. Guha, A. Druin, J.A. Fails, Cooperative inquiry revisited: Reflections of the past and guidelines for the future of intergenerational co-design, Int. J. Child Comput. Interact. 1 (1) (2013) 14-23.

[24] G. Walsh, A. Druin, M.L. Guha, E. Foss, E. Golub, L. Hatley, E. Bonsignore, S. Franckel, Layered Elaboration: a new technique for co-design with children. ComputerHuman Interaction, Atlanta, Georgia, 2010, pp. 1237-1240.

[25] S. Hussain, E.B.N. Sanders, M. Steinert, Participatory design with marginalized people in developing countries: Challenges and opportunities experienced in a field study in Cambodia, Int. J. Des. 6 (2) (2012) 91-109. 
[26] S. Shahid, E.J. Krahmer, Human-Centered design in the developing world: Towards designing didactic games for children, in: S. Dray, A. Light, M. Ho, M. Kam, N. Kodagoda, N. Sambasivan, K. Toyama, J. Thomas, et al. (Eds.), The CHI Workshop on Human-Centered Computing in International Development, ACM Press, Boston, 2009.

[27] G.A. Mills-Tettey, J. Mostow, M.B. Dias, T.M. Sweet, S.M. Belousov, M.F. Dias, H. Gong, Improving child literacy in Africa: experiments with an automated reading tutor, in: Proceedings of Information and Communication Technologies and Development, (ICTD), IEEE, 2009, pp. 129-138.

[28] E. Mazzone, Designing with Children: Reflections on Effective Involvement of Children in the Interaction Design Process (Ph.D. thesis), University of Central Lancashire, 2012. [29] A. Holt, Adolescent-to-Parent Abuse: Current Understandings in Research Policy and Practice, The Policy Press, Great Britain, 2013.

[30] O.S. Iversen, C. Dindler, E.I.K. Hansen, Understanding teenagers' motivation in participatory design, Int. J. Child-Comput. Interact. 1 (3) (2013) 82-87.

[31] D. Fitton, J.C. Read, M.M. Horton, The challenge of working with teens as participants in interaction design, in: CHI'13 Extended Abstracts on Human Factors in Computing Systems, ACM, 2013, pp. 205-210.

[32] N. Toth, L. Little, J.C. Read, D. Fitton, M. Horton, Understanding teen attitudes towards energy consumption, J. Environ. Psychol. 34 (2013) 36-44.

[33] J.C. Read, S.J. MacFarlane, C. Casey, Endurability, engagement and expectations: Measuring children's fun, in: Interaction Design and Children Workshop, Eindhoven, Netherland, 2002.

[34] A. Alhussayena, W. Alrasheda, E.I. Mansora, Available online at www.sciencedirect.com ScienceDirect 6th International Conference on Applied Human Factors and Ergonomics and the Affiliated Conferences, AHFE 2015 Evaluating the user experience of playful interactive learning interfaces with children, 2015, pp. 2318-2324. 